\title{
Reciprocal influences between the signalling pathways regulating proliferation and steroidogenesis in adrenal glomerulosa cells
}

\author{
Richard H Foster \\ Programa de Fisiología y Biofísica, Instituto de Ciencias Biomédicas, Facultad de Medicina, Universidad de Chile, Casilla 70005-Correo 7, Santiago, \\ Chile \\ (Requests for offprints should be addressed to R H Foster, Casilla 70005-Correo 7, Santiago, Chile; E-mail: rfoster@machi.med.uchile.cl)
}

\begin{abstract}
The main regulators of aldosterone secretion in adrenal gland zona glomerulosa (ZG) cells are the hormones angiotensin II (Ang II) and adrenocorticotrophin (ACTH) and small increases in the extracellular potassium $\left(\mathrm{K}^{+}\right)$concentration. The action of these agonists is mediated by different signalling systems - ACTH is mediated by cAMP and activation of protein kinase A while Ang II and $\mathrm{K}^{+}$activate two protein kinases, $\mathrm{Ca}^{2+}$-calmodulin-dependent protein kinase (CamK) and diacylglycerol-dependent protein kinase (PKC). Ang II, besides being one of the main agonists for the secretion of aldosterone, also stimulates proliferation of ZG cells, a process mediated by mitogen-activated protein kinases (MAPKs). Recent studies aimed at elucidating the molecular mechanisms underlying cell proliferation have shown that calcineurin is the principal regulator of MAPKs activity. The purpose of this review is to discuss experimental evidence of possible reciprocal influences between the signalling pathways regulating proliferation and steroidogenesis in ZG cells.
\end{abstract}

Journal of Molecular Endocrinology (2004) 32, 893-902

\section{Introduction}

Aldosterone is the principal mineralocorticoid synthesized by the adrenal gland cortex; it plays a fundamental role in electrolyte and water balance due to its action on epithelial cells of the kidney collecting tubule and the distal colon, where it promotes sodium $\left(\mathrm{Na}^{+}\right)$absorption and potassium $\left(\mathrm{K}^{+}\right)$excretion. High aldosterone production, via alterations in mechanisms controlling its biosynthesis, is associated with sodium retention, expansion of plasma volume, and high blood pressure. In the heart, elevated aldosterone levels cause hypertrophy, fibrosis, and loss of tissue electrolyte balance which eventually cause cardiac muscle dysfunction and, consequently, threaten life. Thus, aldosterone synthesis is finely regulated to ensure an appropriate physiological function (Lumbers 1999, Young \& Funder 2000).

Aldosterone is synthesized in zona glomerulosa (ZG) cells which are in the outermost part of the adrenal cortex. In vivo, its secretion is regulated by the hormone angiotensin II (Ang II) and changes in plasmatic $\mathrm{K}^{+}$concentration, independent of the pituitary hormone adrenocorticotrophin (ACTH), which acts in the zona fasciculata regulating synthesis and secretion of glucocorticoids. In vitro, ACTH is a potent stimulator of aldosterone secretion in primary cultures of ZG cells (Muller 1998). Figure 1 illustrates the major signalling pathways and their relationships in the regulation of aldosterone biosynthesis and proliferation in adrenal ZG cells which will be discussed in this review.

\section{Different signalling pathways control aldosterone biosynthesis}

ACTH stimulates aldosterone production through $\mathrm{G}_{\mathrm{s}-\text { protein-coupled receptors that activate cAMP }}$ formation, and by cAMP-dependent protein kinase (PKA) activation (Graham-Smith et al. 1967, Fakunding et al. 1979, Sala et al. 1979, Yoshida et al. 


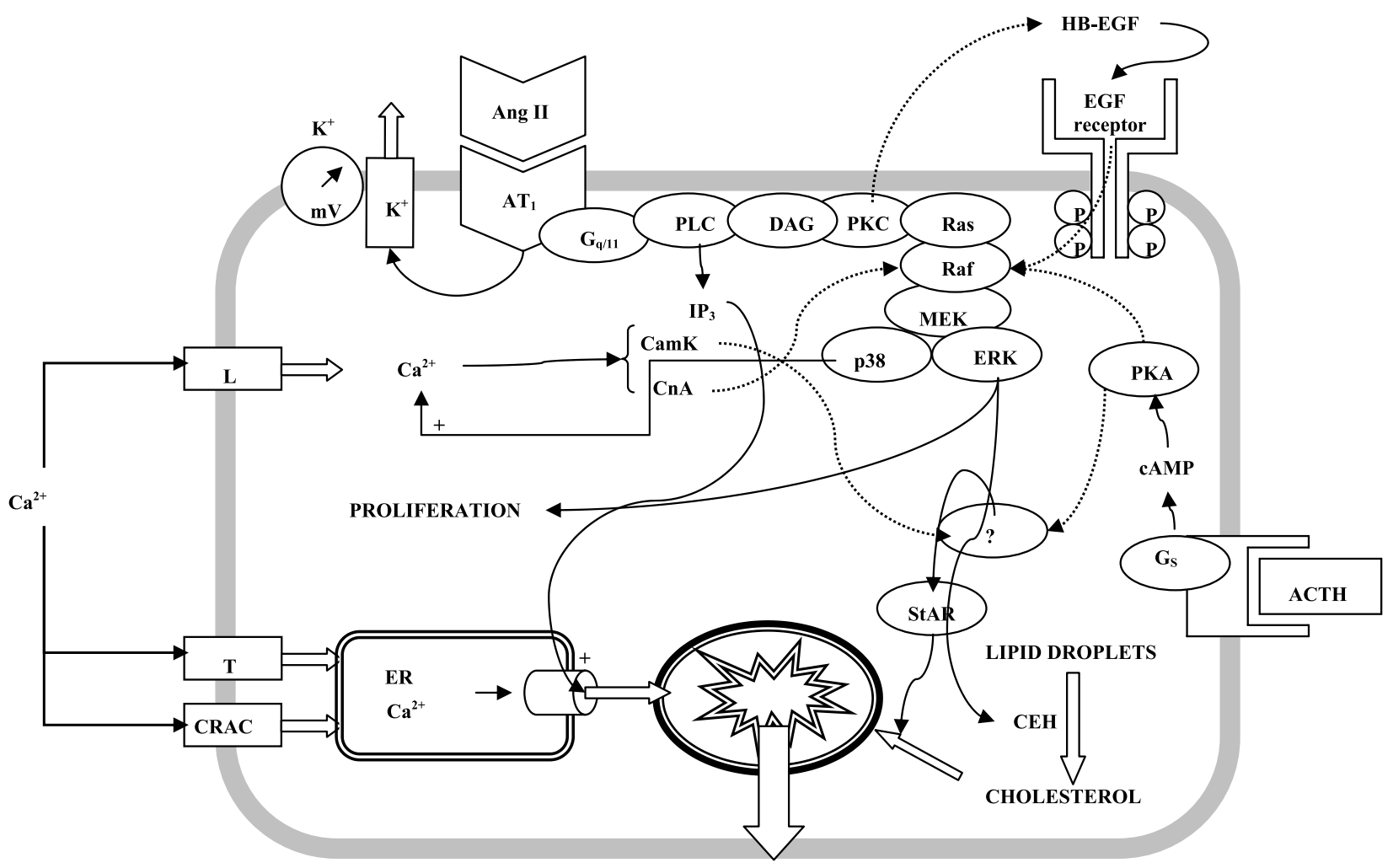

ALDOSTERONE

Figure 1 Model for signalling pathways, interactions and regulators in adrenal ZG cells. Ang II activates $G_{q / 11}$-protein-coupled $A T_{1}$ receptors, leading to the activation of phospholipase C (PLC) and simultaneous formation of inositol 1,4,5-trisphosphate $\left(\mathrm{IP}_{3}\right)$ and diacylglycerol $(D A G)$. $I P_{3}$ binds and activates $\mathrm{IP}_{3}$-receptors localised in discrete domains of the endoplasmic reticulum (ER), opening channels for release of $\mathrm{Ca}^{2+}$ in the vicinity of the mitochondria. DAG binds and activates protein kinase C (PKC). Ang II-AT receptor activation also increases the flow of $\mathrm{Ca}^{2+}$ from the external space through voltage-dependent $\mathrm{Ca}^{2+}$ channels (T- and L-types) and voltage independent $\mathrm{Ca}^{2+}$ release activated channels (CRAC). Binding of adrenocorticotrophin (ACTH) to $\mathrm{G}_{\mathrm{s}}$-protein-coupled receptors leads to the activation of cAMP-dependent protein kinase A (PKA). On the other hand, increases in physiological concentrations of potassium $\left(\mathrm{K}^{+}\right)$open voltage-dependent $\mathrm{Ca}^{2+}$ channels (T- and L-types) without release of $\mathrm{Ca}^{2+}$ from the ER. Ang II, ACTH and small increases in $\mathrm{K}^{+}$concentration induce aldosterone secretion by phosphorylation of the steroid acute regulatory (StAR) protein, an obligatory step in the transfer of cholesterol to the mitochondria. The three agonists, acting through different signalling pathways, activate aldosterone biosynthesis at a site before StAR activation. Additionally, Ang II acting on AT receptors induces cell proliferation through activation of mitogen-activated protein kinases (MAPKs) such as ERK1/2 and p38, which also promote aldosterone biosynthesis. Solid arrows indicate pathways that have been demonstrated. Dotted arrows denote possible signalling pathways and regulators.

1991). In contrast, Ang II and small increases in $\mathrm{K}^{+}$ concentration increase intracellular calcium $\left(\mathrm{Ca}^{2+}\right)$ by several different mechanisms (Fakunding \& Catt 1980, Foster et al. 1981, 1997, Cirillo et al. 1993, which serve as the main intracellular stimuli in aldosterone secretion. The binding of Ang II to $\mathrm{G}_{\mathrm{q} / 11}$-protein-coupled $\mathrm{AT}_{1}$ receptors (Hajnoczky et al. 1992, Ardaillou 1999, de Gasparo et al. 2000) activates phospholipase C-dependent hydrolysis of plasma membrane phosphatidylinositol 4,5bisphosphate, which results in the formation of inositol 1,4,5-trisphosphate $\left(\mathrm{IP}_{3}\right)$ and diacylglycerol (DAG). $\mathrm{IP}_{3}$ causes an increase in $\mathrm{Ca}^{2+}$ cytosolic concentration, initially through rapid release of $\mathrm{Ca}^{2+}$ from intracellular stores and then through a sustained entry of $\mathrm{Ca}^{2+}$ from the 
external space through voltage-dependent ( $\mathrm{T}$ - and L-types) and calcium release activated (CRAC) channels (Foster et al. 1981, 1990, Cohen et al. 1988, Ambroz \& Catt 1992, Burnay et al. 1994). An increase in intracellular $\mathrm{Ca}^{2+}$ activates $\mathrm{Ca}^{2+}$ calmodulin-dependent protein kinase (CamK) (Pezzi et al. 1996), while DAG within the plasma membrane activates protein kinase $\mathrm{G}$ ( $\mathrm{PKC}$ ) (Kojima et al. 1984).

In marked contrast to Ang II, small increases in $\mathrm{K}^{+}$concentration depolarize the cell membrane directly and activate $\mathrm{Ca}^{2+}$ entry through voltagedependent $\mathrm{Ca}^{2+}$ channels without release of $\mathrm{Ca}^{2+}$ from intracellular stores (Foster et al. 1982, Mlinar et al. 1995, Rossier et al. 1996, Foster \& Rojas 1999); this activates CamK (Pezzi et al. 1996). Thus, Ang II elevates cytosolic $\mathrm{Ca}^{2+}$ at the expense of internal and external $\mathrm{Ca}^{2+}$ compartments, while $\mathrm{K}^{+}$increases cytosolic $\mathrm{Ca}^{2+}$ concentration solely at the expense of the external space.

Several studies have demonstrated that these signalling pathways are interrelated. In bovine ZG cells, for example, ACTH inhibits the $\mathrm{Ca}^{2+}$ signal and Ang II-induced aldosterone secretion, a process dependent upon cAMP formation (Yoshida et al. 1991). By contrast, Ang II potentiates the effect of ACTH on cAMP production, and inhibits $\mathrm{K}^{+}$-induced increase in intracellular $\mathrm{Ca}^{2+}$ concentration and aldosterone production (Balla et al. 1991, Aptel et al. 1996).

In spite of the importance of these studies, it has still not been established exactly where cAMP and $\mathrm{Ca}^{2+}$ and their protein kinases come together, especially when both pathways are activated simultaneously.

\section{Steroid acute regulatory (StAR) protein and aldosterone biosynthesis}

The limiting step in aldosterone biosynthesis, as for all steroid hormones, is the conversion of cholesterol to pregnenolone, a reaction catalysed by the cytochrome $\mathrm{P} 450_{\text {scc }}$ which is localized in the internal mitochondrial matrix (Stocco 2001). Steroid secreting cells store steroids in minimal quantities and thus the regulation of steroid secretion is linked directly to the level of steroid synthesis. ACTH, through cAMP and PKA activation, and Ang II, through increased $\mathrm{Ca}^{2+}$ concentration, may regulate the process slowly through the transcription of genes that encode enzymes participating in steroid hormone synthesis. However, transcription and translation mechanisms are not fast enough to account for steroidogenesis activation on the time scale observed. In adrenal ZG cells, for example, increased aldosterone production is clearly detectable within minutes in response to Ang II and ACTH (Foster \& Rasmussen 1983, Foster et al. 2002) and returns to basal levels within minutes after withdrawal of the hormone. The ability to induce steroid hormone synthesis within minutes is facilitated by the transport of cholesterol from the external to the internal mitochondrial membrane, a process that depends upon de novo synthesis of steroid acute regulatory (StAR) protein (Crivello \& Jefcoate 1980, Stocco 2001).

It is not yet known how StAR transfers cholesterol to the internal mitochondrial membrane. It has been proposed that StAR is synthesized rapidly in the cytoplasm from a $37 \mathrm{kDa}$ precursor that is phosphorylated and proteolytically processed during the transport of cholesterol to the internal mitochondrial membrane (Arakane et al. 1997, Artemenko et al. 2001). The regulation and activation of StAR phosphorylation has been studied mainly in cells stimulated through cAMP production, such as Leydig tumour cells (Manna et al. 1999), granulosa cells (lines rLHR-4 and rFSHR-17) (Seger et al. 2001) and Y1 cells (Jones et al. 2000). In bovine ZG cells, Ang II, ACTH and $\mathrm{K}^{+}$all activate StAR expression and phosphorylation (Betancourt-Calle et al. 2001) in concentrations that produce comparable effects in aldosterone production. Although the three agonists initially act through different signalling pathways, it seems likely that their pathways merge at a common site for the activation of aldosterone biosynthesis. However, there are no experimental data regarding StAR expression and phosphorylation that explain the inhibitory effect of ACTH on Ang II-induced intracellular $\mathrm{Ca}^{2+}$ increase and aldosterone secretion (Yoshida et al. 1991), the potentiation effect of Ang II on ACTH-induced cAMP production (Baukal et al. 1994), or the inhibitory effect of Ang II on $\mathrm{K}^{+}$-induced aldosterone production (Balla et al. 1991, Aptel et al. 1996). Considering these three effects leads one to hypothesize that in ZG cells the different pathways converge at some point before StAR activation. 


\section{Mitogen-activated protein kinases and their relationship with steroidogenesis}

Besides their effects on aldosterone secretion, Ang II and ACTH both have important effects on cell proliferation through the activation of mitogenactivated protein kinases (MAPKs). MAPKs are protein kinases whose function and regulation are highly conserved from yeasts to humans. They are activated by stimuli ranging from growth factors and cytokines to hormones and neurotransmitters, which act by activating both tyrosine kinase receptors and G-protein-coupled receptors. The basic arrangement consists of a G-protein (Ras) and three kinases aligned downstream. GTP-activated Ras binds to Raf and translocates it from the cytosol to the plasma membrane, where kinase activation takes place. Activated Raf then phosphorylates MAPK kinase (MEK) which, in turn, phosphorylates and activates MAPKs (MEKs). The MAPKs include extracellular-signal-regulated kinase ERK1/2, c-Jun N-terminal kinase and MAPK p38. These kinases are activated by dual phosphorylation of threonine and tyrosine residues recognised by MEK, which itself is activated by Raf, and also by dual phosphorylation of threonine and tyrosine residues. Following activation, MAPKs may translocate to the nucleus and regulate gene transcription factors related to cellular proliferation, or may regulate processes at the cytoplasmic or plasma membrane level (Widmann et al. 1999, Kolch 2000).

Ang II has been linked with hypertension, cardiac tissue remodelling and cardiac hypertrophy. Its effects are primarily due to Ang II-dependent activation of $\mathrm{AT}_{1}$ receptors, a process accompanied by stimulation of $\mathrm{Ras}$ and the sequence of kinases aligned downstream, culminating in MAPKs activation (de Gasparo et al. 2000). In recent years, there has been a great deal of investigation to elucidate the hypertrophic and proliferating effects of Ang II observed in a variety of its target cells, such as vascular smooth muscle cells (Geisterfer et al. 1988, Dubey et al. 1992, Touyz et al. 2001), cardiac fibroblasts (Sadoshima \& Izumo 1993, Peng et al. 2002, Seta \& Sadoshima 2003) and cardiomyocytes (Paradis et al. 2000, Thomas et al. 2002).

The signalling mechanism of the Ang II-type $\mathrm{AT}_{1}$ receptor has been traditionally linked to the activation of phospholipase $\mathrm{C}$ and its signalling molecules, $\mathrm{IP}_{3}$ and diacylglycerol, with the concomitant increase in intracellular $\mathrm{Ca}^{2+}$ concentration and activation of PKC. However, activation of the $\mathrm{AT}_{1}$ receptor by Ang II also involves tyrosine phosphorylation, and the key question to solve has been how $\mathrm{AT}_{1}$ receptors, which lack the intrinsic tyrosine kinase possessed by receptor tyrosine kinases such as platelet-derived growth factor receptor or epidermal growth factor (EGF) receptor, induce tyrosine phosphorylation, MAPKs activation, hypertrophy and proliferation. Recent investigations have demonstrated that a major pathway for Ang II-induced hypertrophy is mediated by $\mathrm{AT}_{1}$-dependent transactivation of EGF receptor (Shah \& Catt 2003). For example, in neonatal cardiomyocytes infected with an adenovirus that expresses functional $\mathrm{AT}_{1}$ receptors, $\mathrm{Ang}$ II stimulated hypertrophy, EGF receptor phosphorylation and MAPK activation, all effects that are inhibited either by the MAPK kinase inhibitor PD98059 or the EGF receptor antagonist AG1478. In contrast, in non-infected cardiomyocytes, which express undetectable levels of endogenous $\mathrm{AT}_{1}$ receptors, Ang II failed to promote tyrosine phosphorylation of the EGF receptor (Thomas et al. 2002).

The mechanism by which Ang II transactivates the EGF receptor has recently begun to emerge. Intracellular $\mathrm{Ca}^{2+}$ and PKC have been associated with $\mathrm{AT}_{1}$-dependent transactivation of the $\mathrm{EGF}$ receptor; however the experimental results appear to be contradictory. For example, in vascular smooth muscle cells Ang II induced transactivation of the EGF receptor in a $\mathrm{Ca}^{2+}$-dependent manner (Eguchi et al. 2001); however, in cultured neonatal cardiomyocytes, Ang II induced transactivation of the EGF receptor, and MAPKs activation occurred independently of $\mathrm{Ca}^{2+}$ and PKG (Thomas et al. 2002). Also in neonatal cardiomyocytes, Ang II induced activation of ERK1/2 via $\mathrm{PKC}$ but not tyrosine kinases (Zou et al. 1996). The causes of the different responses to Ang II in these studies are not known, but might include different cell types and different species from which neonatal cardiomyocytes are prepared.

A major breakthrough in the understanding of the mechanism of EGF receptor transactivation was the discovery that cultured human macrophages secrete a heparin-binding EGF-like growth factor (HB-EGF) that upon binding to EGF receptors promotes mitogenic effects in fibroblasts 
and vascular smooth muscle cells (Higashiyama et al. 1991, Prenzel et al. 1999). Consistent with these findings, it was later demonstrated that HB-EGF mRNA is highly expressed in the hypertrophied left ventricle of spontaneously hypertensive rats (Fujino et al. 1998) and in rat hearts after myocardial infarction (Tanaka et al. 2002). Moreover, Ang II-induced EGF receptor transactivation in vascular smooth muscle cells and cardiomyocytes is mediated by HB-EGF and requires metalloprotease-dependent cleavage of pro-heparin-binding EGF (Saito et al. 2002, Thomas et al. 2002).

Whether Ang II-induced $\mathrm{AT}_{1}$-dependent transactivation of the $\mathrm{EGF}$ receptor plays a role in adrenal ZG cells has not yet been documented; however, Ang II acting on the $\mathrm{AT}_{1}$ receptor increases the incorporation of thymidine into DNA and increases cell proliferation in primary cultures of bovine adrenal ZG cells (Tian et al. 1995). Consistent with these effects, Ang II induces activation of Raf and ERK1/2 (Tian et al. 1998, Smith et al. 1999) in a time-dependent manner, which is detectable within $1 \mathrm{~min}$, reaches a maximum at $5 \mathrm{~min}$, and gradually returns to the basal level during the next $60 \mathrm{~min}$. Subjecting the cells to a short treatment with the phorbol ester, phorbol myristylacetate (PMA), also phosphorylates and activates ERK1/2 in a time-dependent manner. ERK1/2 phosphorylation and activation reach a maximum at $5 \mathrm{~min}$, which correlates with the time required for maximal phosphorylation and activation of ERK1/2 stimulated by Ang II, suggesting that PKC has a role in Ang IIdependent phosphorylation and activation of ERK1/2 (Tian et al. 1998).

The time taken for phosphorylation of Raf differs substantially from that of its activation. Ang II induces activation of Raf within $1 \mathrm{~min}$, peaks at 5 min and declines thereafter reaching basal levels after $60 \mathrm{~min}$ (Tian et al. 1998), which correlates with the time course of ERK1/2 phosphorylation and activation. However, phosphorylation of Raf is first seen $5 \mathrm{~min}$ after the hormone is added and remains constant for $60 \mathrm{~min}$, suggesting that Ang II-induced phosphorylation of Raf is not associated with the activation of the kinase, but rather with its deactivation (Tian et al. 1998). On the other hand, incubation of the cells in $\mathrm{Ca}^{2+}$-free medium containing EGTA potentiates Raf activation in response to Ang II (Smith et al. 1999), indicating that external $\mathrm{Ca}^{2+}$ has a negative regulatory influence on Raf activation.

Studies on the role of MAPKs in aldosterone biosynthesis have provided important evidence for cross-talk between Ang II-dependent proliferation and steroidogenesis. In bovine adrenal ZG cells, Ang II increases cholesterol supply to the mitochondria by ERK1/2-dependent phosphorylation of cholesterol ester hydrolase (Cherradi et al. 2003), and diminishes the activity of the $\mathrm{Na}^{+} / \mathrm{Ca}^{2+}$ exchanger through MAPK p38, reducing $\mathrm{Ca}^{2+}$ loss from the cytosol, and contributing to the maintenance of the cytosolic $\mathrm{Ca}^{2+}$ concentration required for full aldosterone response (Startchik et al. 2002). However, the authors of this latter study did not determine if specific inhibition of MAPK p38 affected Ang II-induced aldosterone production.

In a recent, rigorous investigation using two cell lines derived from granulosa cells (rLHR-4 and rFSH-17), Seger et al. (2001) reported that the gonadotrophins luteinizing hormone $(\mathrm{LH})$ and follicle-stimulating hormone (FSH) activate ERK1/2 and also increase progesterone secretion. These authors obtained similar effects using forskolin and 8-Br-cAMP, confirming that the action of the two hormones is mediated by cAMP in both processes. However, incubating the cells with the MEK inhibitor PD98059 for 15 min prior to adding the hormone, which inhibits ERK1/2 activation, notably potentiated the effect of $\mathrm{LH}$ and FSH on progesterone production. Consistent with this effect, PD98059 dramatically potentiated StAR expression in response to LH/FSH and forskolin/ 8-Br-cAMP. These findings suggest that the potentiation of steroidogenesis by MEK inhibition occurs after PKA activation, and that the signal cascade after ERK1/2 activation may downregulate steroidogenesis acting at the beginning of the cascade before StAR expression.

Experimental results on the effect of ACTH on MAPK activation are also scarce. In Y1 cells, for example, ACTH stimulates the phosphorylation and activation of MEK and ERK1/2 (Le \& Schimmer 2001) while in bovine adrenal fasciculata cells, ACTH, which stimulates steroidogenesis via cAMP, does not activate ERK1/2 and completely blocks ERK1/2 activation induced by Ang II (Chabre et al. 1995). No information is available at present with respect to the effects of $\mathrm{ACTH}$ and $\mathrm{K}^{+}$ on MAPK in ZG cells. 


\section{Possible role of calcineurin in steroidogenesis and MAPK activation}

Reports on Raf activation in ZG cells (Tian et al. 1998, Smith et al. 1999) suggest that $\mathrm{Ca}^{2+}$ and PKC regulate Raf activity through a phosphorylationdephosphorylation mechanism. Experimental evidence supports this argument. First, it has been shown that PKA inhibits Raf kinase activity through phosphorylation of serine 259 (ser259). Release from its inactive state is brought about by dephosphorylation of this same serine, an indispensable step for efficient recruitment of Raf to the plasma membrane (Dhillon et al. 2002a,b, Kubicek et al. 2002). This dephosphorylation is blocked by okadaic acid (OA), an inhibitor of protein phosphatase PP2A, indicating that PP2A participates in Raf activation. Once Raf is in position on the cell membrane, it is activated by its dissociation from Raf kinase inhibitory protein (RKIP), a process dependent upon phosphorylation of RKIP by PKC at serine 153 (ser153) (Corbit et al. 2003).

Secondly, we have recently demonstrated (Foster et al. 2002) that OA inhibits ACTH-induced aldosterone production completely, but has only a modest effect on Ang II and $\mathrm{K}^{+}$. These results led us to suggest that another phosphatase, distinct from PP2A and regulated by intracellular $\mathrm{Ca}^{2+}$, could be involved in control of aldosterone secretion in response to Ang II and $\mathrm{K}^{+}$. This phosphatase could be calcineurin $(\mathrm{CnA})$, which is also expressed in adrenal cells (Widmaier \& Hall 1987, Kubo \& Strott 1989).

$\mathrm{CnA}$ is a serine/threonine protein phosphatase controlled by intracellular $\mathrm{Ca}^{2+}$ and calmodulin, and plays a critical role in the signalling pathway controlling T-lymphocytes activation (Liu et al. 1991, Clipstone \& Crabtree 1992, Glipstone et al. 1994). CnA is a heterodimer composed of a $19 \mathrm{kDa}$ regulatory subunit and a $60 \mathrm{kDa}$ catalytic subunit, which contains the binding site for calmodulin (Stemmer \& Klee 1994, Sago et al. 1996).

The importance of $\mathrm{CnA}$ in the regulation of the immune cell function is based on the discovery that the immunosuppressants cyclosporine A (CsA) and FK506 are specific inhibitors of $\mathrm{CnA}$ in T-lymphocytes. CsA and FK506 form complexes with their respective intracellular binding proteins, cyclophylin A and FKBP12, which, in turn, bind to and inhibit CnA activity (Liu et al. 1991, Clipstone et al. 1994). Inhibition of CnA by CsA and FK506 blocks the dephosphorylation of activated T-cell transcription factors (NFATs) (Tocci et al. 1989, Loh et al. 1996, Timmerman et al. 1996, Batiuk et al. 1997).

NFATs are a family of proteins (NFAT $1-4$, Rao et al. 1997) which reside in the cytoplasm in a phosphorylated form. When the intracellular $\mathrm{Ca}^{2+}$ concentration increases upon stimulation, $\mathrm{CnA}$ becomes activated and interacts directly with NFATs resulting in their rapid dephosphorylation and subsequent translocation to the nucleus.

It has recently been reported that activated $\mathrm{CnA}$ is critical in the development of cardiac hypertrophy. Activation of CnA results in dephosphorylation of NFAT3 and the subsequent interaction of NFAT3 with the cardiac embryonic transcription factor, GATA4, during the development of hypertrophy in primary rat cardiomyocytes. CisA and FK506 block the increase in intracellular $\mathrm{Ca}^{2+}$ and hypertrophy in primary myocytes treated with Ang II (Molkentin et al. 1998). Moreover, transgenic mice expressing the constitutively active form of $\mathrm{CnA}$ developed a dramatic increase in heart size relative to their nontransgenic littermates. After treatment of the transgenic mice with CsA the size of the heart was not significantly different from the heart of nontransgenic littermates (Molkentin et al. 1998). More recently, it has been demonstrated by RT-PCR analysis that the four members of the NFAT (1-4) family are expressed, at the protein level, in ventricular myocytes, and are able to translocate to the nucleus after infection of the myocytes with an adenovirus expressing the constitutive form of activated $\mathrm{CnA}$, or after stimulation with endothelin-1 (Van Rooij et al. 2003). The CnA/NFAT signalling pathway has also been associated with vascular development (Graef et al. 2001) and skeletal muscle remodelling (Crabtree \& Olson 2002), indicating that the NFAT family members are expressed not only in T-cells but also in other cell types in response to a variety of external signals. Whether NFAT proteins are expressed in adrenal ZG cells is unknown; however, it is plausible that CnA through an NFAT independent mechanism regulates aldosterone biosynthesis or adrenal ZG cell proliferation, acting over other substrates. CnA could dephosphorylate RKIP, causing its reassociation with Raf (Corbit et al. 2003); this would explain the deactivation of Raf activity observed in bovine adrenal ZG cells in response to Ang II (Tian et al. 1998). On the other 
hand, there is evidence that $\mathrm{CnA}$ is expressed in ZG cells (Widmaier \& Hall 1987, Kubo \& Strott 1989). The steroidogenic effect of Ang II in rabbit (Morishita et al. 1990) and rat adrenocortical cells (Mazzocchi et al. 1993) is markedly inhibited by CsA, but dependent aldosterone secretion had little effect on ACTH, and it has been shown that CisA and FK506 completely inhibited Ang II- or PMA-induced potentiation of ACTH-dependent cAMP formation in bovine ZG cells (Baukal et al. 1994), suggesting that the mechanism of the Ang II-induced increase of ACTH-stimulated cAMP formation is mediated by $\mathrm{CnA}$.

The hypothesis that $\mathrm{CnA}$ may participate in MAPK activation in ZG cells is strengthened by recent studies focused on establishing the molecular basis that underlies cardiac hypertrophy. These studies have found that $\mathrm{CnA}$ is associated with MAPK activation and intracellular $\mathrm{Ca}^{2+}$; $\mathrm{CnA}$ is therefore posited as the principal physiological regulator of cardiac hypertrophy. CsA and FK506 retard cardiac hypertrophy, collagen accumulation and CnA activity in animals submitted to blood pressure overload (Meguro et al. 1999, Lim et al. 2000, Bueno \& Molkentin 2002). Transgenic mice that overexpress the dominant negative mutant of CnA, especially in the heart, display significantly less size and weight increase of cardiac muscle in response to blood pressure overload as compared with nontransgenic mice (Zou et al. 2001a). In mouse cardiomyocytes, Ang II activates $\mathrm{CnA}$ and induces phosphorylation and activation of ERK1/2, MAPK p38, and c-jun, effects which are completely inhibited by CsA and FK506, and in mice displaying hypertrophy due to chronic high blood pressure, CsA completely blocks the increase in heart mass (Murat et al. 2000).

The relationship between intracellular $\mathrm{Ca}^{2+}$, CnA activation and ERK1/2 has been elegantly demonstrated by Zou et al. (2001b). These investigators studied the effect of isoproterenol in neonatal rat cardiomyocyte primary cell cultures and observed that isoproterenol increased cardiomyocyte size and activated ERK1/2. The latter effect was completely suppressed in the presence of high EGTA concentration, demonstrating that ERK1/2 activation depends upon external $\mathrm{Ca}^{2+}$. Fluorescence experiments demonstrated that isoproterenol increased the beating velocity of cardiomyocytes and induced an intracellular $\mathrm{Ca}^{2+}$ elevation, which was accompanied by a transient increase in $\mathrm{CnA}$ activity, that became significant at $1 \mathrm{~min}$, maximized at $5 \mathrm{~min}$, and lasted up to $30 \mathrm{~min}$. Isoproterenol phosphorylates and activates Raf, a process blocked by CsA, suggesting that $\mathrm{CnA}$ is engaged as a positive regulator of ERK1/2 activation.

\section{Conclusions}

In the last few years, considerable effort has been made to support the concept that the signalling pathways that mediate the steroidogenic function in adrenal ZG cells, in response to their agonists, interact either negatively or positively in their effect on aldosterone production. All these studies have measured either $\mathrm{Ca}^{2+}$ fluxes or cAMP formation, processes that occur mainly at the plasma membrane, and have assessed the final product which is aldosterone. That adrenal ZG cells secrete aldosterone has been extensively documented, but the underlying molecular mechanisms that couple the Ang II-AT ${ }_{1}$ receptor activated by Ang II at the cell membrane with the mitochondrial events, remains to be understood. The key step in aldosterone biosynthesis, as for all steroid hormones, is the transfer of cholesterol to the internal mitochondrial membrane. This process is assisted by StAR, and it is not known whether the interaction of the $\mathrm{Ca}^{2+}$ and cAMP messenger system converge before StAR phosphorylation and activation. Therefore, it appears that further efforts should be made to identify the site or sites at which these two signalling pathways interact.

Ang II, besides being one of the main agonists for the secretion of aldosterone, also stimulates proliferation of adrenal ZG cells through $\mathrm{AT}_{1}$-dependent activation of MAPKs. However, Ang II-dependent activation of $\mathrm{AT}_{1}$ receptors exerts proliferating and hypertrophic effects in other target cells such as epithelial cells, vascular smooth muscle cells, fibroblasts and cardiomyocytes. A large and significant amount of experimental evidence indicates that activated $\mathrm{AT}_{1}$ receptors transactivate EGF receptor and thereby activation of MAPKs.

Whether the $\mathrm{AT}_{1}$-dependent activation of the EGF signalling pathway exists in adrenal ZG cells is as yet unknown. However, it is known that in adrenal fasciculata cells that also express $\mathrm{AT}_{1}$ receptors, ERK $1 / 2$ is activated by receptor tyrosine kinase activation. 
Experimental studies on the role of calcineurin $(\mathrm{CnA})$ in cardiomyocytes have demonstrated that CnA mediates the effect of the Ang II-AT ${ }_{1}$ receptor activated by Ang II. However, despite the evidence that $\mathrm{CnA}$ participates in adrenal steroidogenesis, not many attempts have been made to define its role and sites of action either on the signalling pathways that mediate steroidogenesis or on the signalling pathways that mediate proliferation.

Finally, the studies discussed in the present review raise several questions, the most important of which are: does the Ang $\mathrm{II}_{-} \mathrm{AT}_{1}$ receptor transactivate the EGF receptor in adrenal ZG cells? What effect do ACTH and $\mathrm{K}^{+}$have on MAPKs activity? Do Ang II and $\mathrm{K}^{+}$activate $\mathrm{CnA}$, and if so, how does this activity relate to aldosterone secretion and proliferation?

\section{Acknowledgements}

This work was supported by Grant 1981106 from FONDECYT.

\section{References}

Ambroz C \& Catt KJ 1992 Angiotensin II receptor-mediated calcium influx in bovine adrenal glomerulosa cells. Endocrinology $131408-414$

Aptel HV, Johnson EIM, Valloton MB, Rossier MF \& Capponi AM 1996 Demonstration of an angiotensin II-induced negative feedback effect on aldosterone synthesis in isolated rat adrenal zona glomerulosa cells. Molecular and Cellular Endocrinology 119 105-111.

Arakane F, King SR, Du Y, Kalle CB, Walsh LP, Watari H, Stocco DM \& Strauss JF III 1997 Phosphorylation of steroidgenic acute regulatory protein (StAR) modulates its steroidogenic activity. Journal of Biological Chemistry 272 32656-32662.

Ardaillou R 1999 Angiotensin II receptors. Fournal of the American Society for Nephrology 10 S30-S39.

Artemenko IP, Zhao D, Hales DB, Hales KH \& Jefcoate CR 2001 Mitochondrial processing of newly synthesized steroidogenic acute regulatory protein (StAR), but not total StAR, mediates cholesterol transfer to cytochrome P450 side chain cleavage enzyme in adrenal cells. Fournal of Biological Chemistry 276 46583-46596.

Balla T, Holló Z, Várnai P \& Spät A 1991 Angiotensin II inhibits $\mathrm{K}^{+}$-induced $\mathrm{Ca}^{2+}$ signal generation in rat adrenal glomerulosa cells. Biochemical fournal 273 399-404.

Batiuk TD, Kung L \& Halloran PF 1997 Evidence that CnA is rate-limiting for primary human lymphocyte activation. Fournal of Clinical Investigation 100 1894-1901.

Baukal AJ, Hunyady L, Catt KJ \& Balla T 1994 Evidence for participation of $\mathrm{CnA}$ in potentiation of agonist-stimulated cyclic AMP formation by the calcium-mobilizing hormone angiotensin II. Fournal of Biological Chemistry $26924546-24549$.

Betancourt-Calle S, Calle RA, Isales CM, White S, Rasmussen H \& Bollag W 2001 Differential effects of agonists of aldosterone secretion on steroidogenic acute regulatory phosphorylation. Molecular and Cellular Endocrinology 173 87-94.

Bueno OF \& Molkentin JD 2002 Involvement of extracellular signal-regulated kinases $1 / 2$ in cardiac hypertrophy and cell death. Circulation Research 91 776-781.

Burnay MM, Phyton CP, Valloton MB, Capponi AM \& Rossier MF 1994 Role of the capacitative calcium influx in the activation of steroidogenesis by angiotensin II in adrenal glomerulosa cells. Endocrinology 135 751-758.

Chabre O, Cornillon F, Bottari SP, Chambaz EM \& Vilgrain I 1995 Hormonal regulation of mitogen-activated protein kinase activity in bovine adrenocortical cells: cross-talk between phosphoinositides, adenosine $3^{\prime}, 5^{\prime}$-monophosphate, and tyrosine kinase receptor pathways. Endocrinology 136 956-964.

Cherradi N, Pardo B, Greenberg AS, Kraemer FB \& Capponi AM 2003 Angiotensin II activates cholesterol ester hydrolase in bovine glomerulosa cells through phosphorylation mediated by p42/p44 mitogen-activated protein kinase. Endocrinology 144 $4905-4915$

Cirillo M, Quinn SJ \& Canessa ML 1993 Early and late effects of angiotensin-II on $\mathrm{Ca}^{2+}$ fluxes in bovine adrenal glomerulosa cells. Endocrinology 132 1921-1930.

Clipstone NA \& Crabtree 1992 Identification of calcineurin as a key signalling in T-lymphocyte activation. Nature $\mathbf{3 5 7}$ 695-697.

Clipstone NA, Fiorentino DF \& Crabtree GR 1994 Molecular analysis of the interaction of calcineurin with drug-immunophilin complexes. Fournal of Biological Chemistry 269 26431-26437.

Cohen JC, McCarthy RT, Barrett PQ \& Rasmussen H $1988 \mathrm{Ca}^{2+}$ channels in adrenal glomerulosa cells: $\mathrm{K}^{+}$and angiotensin II increase T-type Ca channel current. PNAS 85 2412-2416.

Corbit KC, Trakul N, Eves EM, Diaz B, Marshall M \& Rosner MR 2003 Activation of raf- 1 signaling by protein kinase C through a mechanism involving raf kinase inhibitory protein. Fournal of Biological Chemistry 278 13061-13068.

Crabtree GR \& Olson EN 2002 NFAT signaling: choreographing the social life of cells. Cell $\mathbf{1 0 9}$ S67-S69.

Crivello JF \& Jefcoate CR 1980 Intracellular movement of cholesterol in rat adrenal cells. Kinetics and effects of inhibitors. Fournal of Biological Chemistry 255 8144-8151.

Dhillon AS, Meikle S, Yazici Z, Eulitz M \& Kolch W $2002 a$ Regulation of Raf- 1 activation and signalling by dephosphorylation. EMBO fournal 21 64-71.

Dhillon AS, Pollock C, Steen H, Shaw PE, Mischak H \& Kolch W $2002 b$ Cyclic AMP-dependent kinase regulates Raf-1 kinase mainly by phosphorylation of serine 259. Molecular and Cellular Biology 22 3237-3246.

Dubey RK, Roy A \& Overbeck HW 1992 Culture of renal arteriolar smooth muscle cells. Mitogenic responses to angiotensin II. Circulation Research 71 1143-1152.

Eguchi S, Dempsey PJ, Frank GD, Motley ED \& Inagami T 2001 Activation of MAPKs by angiotensin II in vascular smooth muscle cells. Fournal of Biological Chemistry 276 7957-7962.

Fakunding JL \& Catt KJ 1980 Dependence of aldosterone stimulation in adrenal glomerulosa cell on calcium uptake: effects of lanthanum and verapamil. Endocrinology 107 1345-1353.

Fakunding JL, Chow R \& Catt KJ 1979 The role of calcium in the stimulation of aldosterone production by adrenocorticotropin, angiotensin II, and potassium in isolated glomerulosa cells. Endocrinology 105 327-333.

Foster R \& Rasmussen H 1983 Angiotensin-mediated calcium eflux from adrenal glomerulosa cells. American fournal of Physiology $\mathbf{2 4 5}$ E281-E287.

Foster RH \& Rojas AM 1999 Evidence suggesting that the angiotensin II-sensitive intracellular $\mathrm{Ca}^{2+}$ pool is reloaded from the external space in adrenal glomerulosa cells. General Pharmacology 32 171-177. 
Foster R, Lobo MV, Rasmussen H \& Marusic ET 1981 Calcium: its role in the mechanism of action of angiotensin II and potassium in aldosterone production. Endocrinology 109 2196-2201.

Foster R, Lobo MV, Rasmussen H \& Marusic ET 1982 The effect of calcium on potassium-induced depolarization of adrenal glomerulosa cells. FEBS Letters 149 253-256.

Foster RH, Davis JS \& Farese RV 1990 External calcium is required for activation of phospholipase C by angiotensin II in adrenal glomerulosa cells. Molecular and Cellular Biochemistry 95 57-166.

Foster RH, MacFarlane CH \& Bustamante MO 1997 Recent progress in understanding aldosterone secretion. General Pharmacology 28 647-651.

Foster RH, Casado A, Bakal F, Catalan L \& Pino M 2002 Okadaic acid inhibits angiotensin II, adrenocorticotropin and potassium-dependent aldosterone secretion. Fournal of Steroid Biochemistry and Molecular Biology 80 331-337.

Fujino T, Hasebe N, Fujita M, Takeuchi K, Kawabe J, Tobise K, Higashiyama S, Taniguchi N \& Kikuchi K 1998 Enhanced expression of heparin-binding EGF-like growth factor and its receptor in hypertrophied left ventricle of spontaneously hypertensive rats. Cardiovascular Research 38 365-374.

de Gasparo M, Catt KJ, Inagami T, Wright JW \& Unger T 2000 International Union of Pharmacology. XXIII. The angiotensin II receptors. Pharmacological Reviews 52 415-472.

Geisterfer AAT, Peach MJ \& Owens GK 1988 Angiotensin II induces hypertrophy, not hyperplasia, of cultured rat aortic smooth muscle cells. Circulation 62 749-756.

Graef IA, Chen F, Chen L, Kuo A \& Crabtree GR 2001 Signals transduced by $\mathrm{Ca}^{2+} /$ calcineurin and NFATc3/c4 pattern the developing vasculature. Cell $\mathbf{1 0 5} 863-875$.

Graham-Smith DG, Butcher RW, Ney RL \& Sutherland EW 1967 Adenosine 3', $5^{\prime}$-monophosphate as the intracellular mediator of the action of adrenocorticotropin hormone on the adrenal cortex. Fournal of Biological Chemistry 242 5535-5541.

Hajnoczky G, Csordas G, Bago A, Chiu AT \& Spat A 1992 Angiotensin II exerts its effect on aldosterone production and potassium permeability through receptor subtype AT1 in rat adrenal glomerulosa cells. Biochemical Pharmacology 43 $1009-1012$

Higashiyama S, Abraham JA, Miller J, Fiddes JC \& Klagsbrun M 1991 A heparin-binding growth factor secreted by macrophage-like cells that is related to EGF. Science $\mathbf{2 5 1}$ 936-939.

Jones PM, Sayed SB, Persaud SJ, Burns CJ, Gyles S \& Whitehouse BJ 2000 Cyclic AMP-induced expression of steroid acute regulatory protein is dependent upon phosphoprotein phosphatases activities. Fournal of Molecular Endocrinology $\mathbf{2 4}$ 233-239.

Kojima I, Kojima K, Kreutter D \& Rasmussen H 1984 The temporal integration of the aldosterone secretory response to angiotensin II occurs via two intracellular pathways. Fournal of Biological Chemistry 259 14448-14457.

Kolch W 2000 Meaningful relationships: the regulation of the Ras/Raf/MEK/ERK pathway by protein interactions. Biochemical Journal 351 289-305.

Kubicek M, Pacher M, Abraham D, Podar K, Eulitz M \& Baccarini M 2002 Dephosphorylation of ser-259 regulates Raf-1 membrane association. Fournal of Biological Chemistry 277 7913-7919.

Kubo M \& Strott CA 1989 Calmodulin-binding proteins in subcellular fractions of zones of the adrenal cortex. Fournal of Steroid Biochemistry and Molecular Biology 33 357-363.

Le T \& Schimmer BP 2001 The regulation of MAPKs in Y1 mouse adrenocortical tumor cells. Endocrinology 142 4282-4287.

Lim HW, De Windt LJ, Steiberg L, Taigen T, Witt SA, Kimball TR \& Molkentin JD 2000 CnA expression, activation, and function in cardiac pressure-overload hypertrophy. Circulation 101 $2431-2437$.
Liu J, Farmer JD, Lane WS, Friedman J, Weissman I \& Schreiber SL 1991 Calcineurin is a common target of cyclophilincyclosporin A and FK 506 complexes. Cell 66 807-815.

Loh C, Carew JA, Kim J, Hogan PK \& Rao A 1996 T-cell receptor stimulation elicits early phase of activation and a later phase of deactivation of the transcription factor NFAT1. Molecular and Cellular Biology 16 3945-3954.

Lumbers ER 1999 Angiotensin and aldosterone. Regulatory Peptides 80 91-100.

Manna PR, Pakarinen P, El-Hefnawy T \& Huhtaniemi IT 1999 Functional assessment of the calcium messenger system in cultured mouse Leydig tumor cells: regulation of human chorionic gonadotropin-induced expression of the steroidogenic acute regulatory protein. Endocrinology 140 1739-1751.

Mazzocchi G, Markowska A, Andreis PG, Tortorella C, Neri G, Gottardo G, Malendowicz LK \& Nussdorfer GG 1993 Effects of cyclosporine-A on steroid secretion of dispersed rat adrenocortical cells. Experimental Toxicology and Pathology 45 481-488.

Meguro T, Hong C, Asai K, Takagi G, McKinsey TA, Olson EN \& Vatner SF 1999 Cyclosporine attenuates pressure-overload hypertrophy in mice while enhancing susceptibility to decompensation and heart failure. Circulation Research $\mathbf{8 4}$ 735-740.

Mlinar B, Biagi BA \& Enyeart JJ 1995 Losartan-sensitive AII receptors linked to depolarization-dependent cortisol secretion through a novel signalling pathway. Fournal of Biological Chemistry $27020942-20951$.

Molkentin JD, Lu J, Antos CL, Markham B, Richardson J, Robbins J, Grant SR \& Olson EN 1998 A calcineurin-dependent transcriptional pathway for cardiac hypertrophy. Cell $\mathbf{9 3}$ 215-228.

Morishita R, Higaki J, Mikami H \& Ogihara T 1990 Effect of cyclosporin A on aldosterone production by dispersed rabbit adreno-capsular cells. Life Sciences 46 1985-1989.

Muller J 1998 Regulation of aldosterone biosynthesis: the end of the road? Clinical and Experimental Pharmacology Suppl 25 S79-S85.

Murat A, Pellieux C, Brunner HR \& Pedrazzini T 2000 Calcineurin blockade prevents cardiac mitogen-activated protein kinase activation and hypertrophy in renovascular hypertension. Fournal of Biological Chemistry 275 40867-40873.

Paradis P, Dali-Youcef N, Paradis WF, Thibaut G \& Nermer M 2000 Overexpression of angiotensin II type 1 receptor in cardiomyocytes induces cardiac hypertrophy and remodeling. PNAS 97 931-936.

Peng J, Gurantz D, Tran V, Cowling RT \& Greenberg BH 2002 Tumor necrosis factor-alpha-induced $\mathrm{AT}_{1}$ receptor upregulation enhances angiotensin II-mediated cardiac fibroblast responses that favor fibrosis. Circulation Research 91 1119-1126.

Pezzi V, Clark BJ, Ando S, Stocco DM \& Rainey WE 1996 Role of calmodulin-dependent protein kinase II in the acute stimulation of aldosterone production. Foumal of Steroid Biochemistry and Molecular Biology 58 417-424.

Prenzel N, Zwick E, Daub H, Leserer M, Abraham R, Wallash C \& Ulrich A 1999 EGF receptor transactivation by G-protein-coupled receptors requires metalloproteinase cleavage of proHB-EGF. Nature $402884-888$.

Rao A, Luo C \& Hogan PG 1997 Transcription factors of the NFAT family: regulation and function. Annual Review of Immunology $15707-747$.

Rossier MF, Burnay MM, Valloton MB \& Capponi AM 1996 Distinct functions of T- and L-type calcium channels during activation of bovine adrenal glomerulosa cells. Endocrinology 137 4817-4826.

Sadoshima J \& Izumo S 1993 Molecular characterization of angiotensin II-induced hypertrophy of cardiac myocytes and hyperplasia of cardiac fibroblasts. Critical role of the $\mathrm{AT}_{1}$ receptor subtype. Circulation Research 73 413-423. 
Sago JK, Fruman DA, Wesselborg S, Walsh CT \& Bierer BE 1996 Competitive inhibition of calcineurin phosphatase activity by its autoinhibitory domain. Biochemical fournal 320 879-884.

Saito S, Frank GD, Motley ED, Dempsey PJ, Utsunomiya H, Inagami T \& Eguchi S 2002 Metalloprotease inhibitor blocks angiotensin II-induced migration through inhibition of epidermal growth factor receptor transactivation. Biochemical and Biophysical Research Communications 294 1023-1029.

Sala GB, Hayashi K, Catt KJ \& Dufau ML 1979 Adrenocorticotropin action in isolated adrenal cells. Fournal of Biological Chemistry 254 3861-3865.

Seger R, Hanoch T, Rosemberg R, Dantes A, Merz WE, Strauss JF III \& Amsterdam A 2001 The ERK signaling cascade inhibits gonadotropin-stimulated steroidogenesis. Fournal of Biological Chemistry 276 13957-13964.

Seta K \& Sadoshima J 2003 Phosphorylation of tyrosine 319 of the angiotensin II type 1 receptor mediates angiotensin II-induced trans-activation of the epidermal growth factor receptor. Fournal of Biological Chemistry 278 9019-9026.

Shah BH \& Catt KJ 2003 A central role of EGF receptor transactivation in angiotensin II-induced cardiac hypertrophy. Trends in Pharmacological Science 24 239-244.

Smith RD, Baukal AJ, Dent P \& Catt KJ 1999 Raf-1 kinase activation by angiotensin II in adrenal glomerulosa cells: roles of $\mathrm{G}_{\mathrm{i}}$, phosphatidylinositol 3-kinase, and $\mathrm{Ca}^{2+}$ influx. Endocrinology $1401385-1391$.

Startchik I, Morabito D, Lang U \& Rossier MF 2002 Control of calcium homeostasis by angiotensin II in adrenal glomerulosa cells through activation of p38 MAPK. Fournal of Biological Chemistry 277 24265-24273.

Stemmer PM \& Klee CB 1994 Dual calcium ion regulation of calcineurin by calmodulin and calcineurin B. Biochemistry $\mathbf{3 3}$ $6859-6866$.

Stocco DM 2001 StAR protein and the regulation of steroid hormone biosynthesis. Annual Review of Physiology 63 193-213.

Tanaka N, Masamura K, Yoshida M, Kato M, Kaway Y \& Miyamori I 2002 A role of heparin-binding epidermal growth factor-like growth factor in cardiac remodeling after myocardial infarction. Biochemical and Biophysical Research Communications 297 375-381.

Thomas WG, Brandenburger Y, Autelitano D, Pham T, Quian H \& Hannan RD 2002 Adenoviral-directed expression of the type la angiotensin receptor promotes cardiomyocyte hypertrophy via transactivation of the epidermal growth factor receptor. Circulation Research 90 135-142.

Tian Y, Balla T, Baukal AJ \& Catt KJ 1995 Growth responses to angiotensin II in bovine adrenal glomerulosa cells. American fournal of Physiology 268 E135-E144.

Tian Y, Smith RD, Balla T \& Catt KJ 1998 Angiotensin II activates mitogen-activated protein kinases via protein kinase $\mathrm{C}$ and
Ras/Raf-1 kinase in bovine adrenal glomerulosa cells. Endocrinology 139 1801-1809.

Timmerman LA, Clipstone NA, Ho SN, Northrop JP \& Crabtree GR 1996 Rapid shuttling of NF-AT in discrimination of $\mathrm{Ca}^{2+}$ signals and immunosuppression. Nature 383 837-840.

Tocci MJ, Matkovich, DA, Collier KA, Kwok P, Dumont F, Lin S, Degudicibus S, Siekierka JJ, Chin J \& Hutchinson NI 1989 The immunosuppressant FK506 selectively inhibits expression of early $\mathrm{T}$ cell activation genes. Fournal of Immunology 143 718-726.

Touyz RM, He G, El Mabrouk M, Diep Q Mardigan V \& Schiffrin EL 2001 Differential activation of extracellular signal-regulated protein kinase $1 / 2$ and p38 mitogen activated-protein kinase by $\mathrm{AT}_{1}$ receptors in vascular smooth muscle cells from Wistar-Kyoto rats and spontaneously hypertensive rats. Fournal of Hypertension $\mathbf{1 9}$ 533-539.

Van Rooij E, Doevendans PA, de Theije CC, Babiker FA, Molkentin JD \& De Windt LJ 2003 Requirement of nuclear factor of activated T-cells in calcineurin-mediated cardiomyocytes hypertrophy. Journal of Biological Chemistry 277 48617-48626.

Widmaier EP \& Hall PF 1987 Calmodulin-binding proteins in plasma membranes from adrenocortical cells. Endocrinology 121 914-923.

Widmann C, Gibson S, Jarpe MB \& Jhonson GL 1999 Mitogen-activated protein kinase: conservation of a three-kinase module from yeast to human. Physiological Reviewes 79 143-180.

Yoshida A, Nishikawa T, Tamura Y \& Yoshida S 1991 ACTH-induced inhibition of the action of angiotensin II in bovine zona glomerulosa cells. Fournal of Biological Chemistry $\mathbf{2 6 6}$ 4288-4294.

Young M \& Funder JW 2000 Aldosterone and the heart. Trends in Endocrinology and Metabolism 11 224-226.

Zou Y, Komuro I, Yamazaki T, Aikawa R, Kudoh S, Shiojima I, Hiroi Y, Mizuno T \& Yazaki Y 1996 Protein kinase C but not tyrosine kinases or ras, plays a critical role in angiotensin II-induced activation of raf-1 kinase and extracellular signal-regulated protein kinases in cardiac myocytes. Fournal of Biological Chemistry 271 33592-33597.

Zou Y, Hiroi Y, Uozumi H, Takimot E, Toko H, Zhu W, Kudoh S, Mizukami M, Shimoyama M, Shibasaki F et al. 2001 a Calcineurin plays a critical role in the development of pressure overload-induced cardiac hypertrophy. Circulation 104 97-101.

Zou Y, Hiroi Y, Yao A, Zhu W, Kudoh S, Hiroi Y, Shimoyama M, Uozumi H, Kohmoto O, Takahashi T et al. $2001 b$ Isoproterenol activates extracellular signal-regulated protein kinases in cardiomyocytes through calcineurin. Circulation 104 102-108.

\section{Received in final form 21 January 2004} Accepted 14 February 2004 